\title{
FIMPEL, Martin, Reichsjustiz und Territorialstaat : Württemberg als Kommissar von Kaiser und Reich im Schwäbischen Kreis (1648-1806)
}

\section{Christophe Duhamelle}

\section{OpenEdition}

\section{Journals}

Édition électronique

URL : http://journals.openedition.org/ifha/1317

DOI : 10.4000/ifha. 1317

ISSN : 2198-8943

Éditeur

IFRA - Institut franco-allemand (sciences historiques et sociales)

Référence électronique

Christophe Duhamelle, «FIMPEL, Martin, Reichsjustiz und Territorialstaat : Württemberg als Kommissar von Kaiser und Reich im Schwäbischen Kreis (1648-1806) », Revue de I'IFHA [En ligne], Date de recension, mis en ligne le 01 janvier 2000, consulté le 22 septembre 2020. URL : http://journals.openedition.org/ ifha/1317 ; DOl : https://doi.org/10.4000/ifha.1317

Ce document a été généré automatiquement le 22 septembre 2020.

(CIFHA 


\title{
FIMPEL, Martin, Reichsjustiz und Territorialstaat: Württemberg als Kommissar von Kaiser und Reich im Schwäbischen Kreis (1648-1806)
}

\author{
Christophe Duhamelle
}

1 Focalisés sur quelques grands procès perdus dans les sables, les historiens ont longtemps considéré que les tribunaux d'Empire, faute de disposer d'organes exécutifs propres, étaient condamnés à l'inefficacité. Mais pourquoi alors auraient-ils rendu un nombre de sentences estimé, entre 1500 et 1806, à 180000 ? C'est que la majorité de ces procès concernaient en fait les petits états d'Empire envers qui, dans les Cercles les plus actifs comme celui de Souabe, les principaux territoires conservaient, comme " commissaires » de la justice impériale, une véritable influence. En étudiant, parmi les 409 cas documentés de commissions impériales confiées au duché de Wurtemberg entre 1648 et 1806, 125 exemples représentatifs, M.F. établit l'importance d'une procédure qui contribue au maintien des structures impériales et à la survie des petits territoires pour qui une commission extérieure est souvent le seul moyen de régler leurs problèmes internes.

2 L'auteur parvient à plusieurs conclusions : les commissions, tout d'abord, sont aux yeux du Wurtemberg une affaire sérieuse. Leur suivi est confié à une instance juridique spécialisée et constitue pour le duc un moyen primordial pour conforter son influence régionale. Plus qu'un simple instrument d'exécution (bien que la force militaire du Cercle, rendue permanente en 1681, intervienne parfois pour ramener l'ordre), il s'agit d'une instance de négociation, qui cherche le compromis avant tout. Louvoyant entre les alliances du duc, la nécessité d'assurer la justice impériale, la concurrence avec l'autre prince dirigeant du Cercle (le catholique prince-évêque de Constance) et les relations avec les Habsbourg, l'action des commissions est un sismographe de l'évolution politique du duché. Les commissions, d'autre part, sont pour les territoires qui y sont soumis à la fois des ingérences parfois mal acceptées et des occasions de 
modernisation, les commissaires apportant avec eux les techniques avancées de la science camérale pour traiter les conflits de juridiction et les problèmes financiers (ceux par exemple des comtes Fugger, désormais perclus de dettes...) qui forment l'essentiel de leur champ d'action. La petite ville d'Empire de Buchhorn profite par exemple en même temps, dans la seconde moitié du XVIIIe s., des enseignements de la commission impériale et des bénéfices d'une alliance économique avec la Bavière (qui ne fait pas partie du même Cercle), illustrant ainsi la complexité et la subtilité de la construction impériale. Enfin, cet ouvrage confirme la reviviscence des rouages impériaux en fin de période, alors que le Wurtemberg, désormais allié des Habsbourg, aide ceux-ci à resserrer, face à la concurrence prussienne, leurs liens avec l'Empire.

3 Bien que le plan de ce livre procède plus par accumulation que par construction, la précision des exemples et la netteté des conclusions en font une contribution importante à la redécouverte de ce que fut, dans sa vivante originalité, le Saint-Empire moderne.

4 Christophe DUHAMELLE 